\title{
Observations of the vertical distributions of summertime atmospheric pollutants and the corresponding ozone production in Shanghai, China
}

\author{
Chengzhi Xing ${ }^{1, *}$, Cheng Liu ${ }^{1,2,3,9, *}$, Shanshan Wang ${ }^{4}, \mathrm{Ka} \mathrm{Lok} \mathrm{Chan}^{5}$, Yang Gao ${ }^{6}$, Xin Huang ${ }^{7}$, Wenjing Su ${ }^{1}$, \\ Chengxin Zhang ${ }^{1}$, Yunsheng Dong ${ }^{3}$, Guangqiang Fan ${ }^{3}$, Tianshu Zhang ${ }^{3}$, Zhenyi Chen ${ }^{3}$, Qihou Hu ${ }^{3}$, Hang Su ${ }^{8,10}$, \\ Zhouqing Xie ${ }^{1,2,3,9}$, and Jianguo $\mathrm{Liu}^{2,3}$ \\ ${ }^{1}$ School of Earth and Space Sciences, University of Science and Technology of China, Hefei, 230026, China \\ ${ }^{2}$ Center for Excellence in Regional Atmospheric Environment, Institute of Urban Environment, \\ Chinese Academy of Sciences, Xiamen, 361021, China \\ ${ }^{3}$ Key Lab of Environmental Optics \& Technology, Anhui Institute of Optics and Fine Mechanics, \\ Chinese Academy of Sciences, Hefei, 230031, China \\ ${ }^{4}$ Shanghai Key Laboratory of Atmospheric Particle Pollution and Prevention (LAP ${ }^{3}$ ), Department of \\ Environmental Science and Engineering, Fudan University, Shanghai, 200433, China \\ ${ }^{5}$ Meteorological Institute, Ludwig-Maximilians-Universität München, Munich, Germany \\ ${ }^{6}$ College of Environmental Science and Engineering, Ocean University of China, Qingdao, 266100, China \\ ${ }^{7}$ School of Atmospheric Sciences, Nanjing University, Nanjing, 210093, China \\ ${ }^{8}$ Institute for Environmental and Climate Research, Jinan University, Guangzhou 511443, China \\ ${ }^{9}$ Anhui Province Key Laboratory of Polar Environment and Global Change, USTC, Hefei, 230026, China \\ ${ }^{10}$ Biogeochemistry Department, Max Planck Institute for Chemistry, Mainz, 55020, Germany \\ *These authors contributed equally to this work.
}

Correspondence to: Shanshan Wang (shanshanwang@ fudan.edu.cn), Ka Lok Chan (lok.chan@lmu.de), and Cheng Liu (chliu81@ustc.edu.cn)

Received: 12 July 2017 - Discussion started: 31 July 2017

Revised: 16 October 2017 - Accepted: 20 October 2017 - Published: 1 December 2017

\begin{abstract}
Ground-based multi-axis differential optical absorption spectroscopy (MAX-DOAS) and lidar measurements were performed in Shanghai, China, during May 2016 to investigate the vertical distribution of summertime atmospheric pollutants. In this study, vertical profiles of aerosol extinction coefficient, nitrogen dioxide $\left(\mathrm{NO}_{2}\right)$ and formaldehyde $(\mathrm{HCHO})$ concentrations were retrieved from MAX-DOAS measurements using the Heidelberg Profile (HEIPRO) algorithm, while vertical distribution of ozone $\left(\mathrm{O}_{3}\right)$ was obtained from an ozone lidar. Sensitivity study of the MAX-DOAS aerosol profile retrieval shows that the a priori aerosol profile shape has significant influences on the aerosol profile retrieval. Aerosol profiles retrieved from MAX-DOAS measurements with Gaussian a priori profile demonstrate the best agreements with simultaneous lidar measurements and vehicle-based tethered-balloon observa-
\end{abstract}

tions among all a priori aerosol profiles. Tropospheric $\mathrm{NO}_{2}$ vertical column densities (VCDs) measured with MAXDOAS show a good agreement with OMI satellite observations with a Pearson correlation coefficient $(R)$ of 0.95 . In addition, measurements of the $\mathrm{O}_{3}$ vertical distribution indicate that the ozone productions do not only occur at surface level but also at higher altitudes (about $1.1 \mathrm{~km}$ ). Planetary boundary layer (PBL) height and horizontal and vertical wind field information were integrated to discuss the ozone formation at upper altitudes. The results reveal that enhanced ozone concentrations at ground level and upper altitudes are not directly related to horizontal and vertical transportation. Similar patterns of $\mathrm{O}_{3}$ and $\mathrm{HCHO}$ vertical distributions were observed during this campaign, which implies that the ozone productions near the surface and at higher al- 
titudes are mainly influenced by the abundance of volatile organic compounds (VOCs) in the lower troposphere.

\section{Introduction}

Air pollution has become one of the major environmental problems around the world. It is particularly serious in China due to the rapid development of the economy and industrialization. This problem directly affects the ecological environment and Earth's radiation budget. It also has a series of adverse impacts on human health. Regional ozone pollution caused by photochemical reaction during summertime has become a serious problem in China in the recent years. Previous studies of the $\mathrm{O}_{3}$ vertical distribution and temporal variation in $\mathrm{O}_{3}$ within the boundary layer in northern China indicated that $\mathrm{O}_{3}$ levels are closely correlated with the abundance of $\mathrm{O}_{3}$ precursors (Tang et al., 2017a, b). The major primary $\mathrm{O}_{3}$ precursors in China are nitrogen oxides $\left(\mathrm{NO}_{x}\right)$, defined as the sum of nitric oxide (NO) and nitrogen dioxide $\left(\mathrm{NO}_{2}\right)$, and volatile organic compounds (VOCs) (Geng et al., 2007). Nitrogen dioxide and formaldehyde (HCHO) are the important constituents in the atmosphere playing key roles in both tropospheric and stratospheric chemistry (Seinfeld and Pandis, 1998; Chan et al., 2015; Wang et al., 2017). $\mathrm{NO}_{2}$ contributes to the formation of secondary aerosols and participate in the catalytic formation of ozone in the troposphere (Crutzen, 1975), while HCHO is one of the most important VOCs that can be used as a proxy for the total VOCs (Sillman, 1995; Duncan et al., 2010).

In the presence of sunlight, VOCs and $\mathrm{NO}_{x}$ contribute together to the formation of ozone in the troposphere (Crutzen, 1975; Seinfeld and Pandis, 1998). The ambient ozone level strongly depends on both the relative and absolute amounts of VOCs and $\mathrm{NO}_{x}$ (Geng et al., 2007; Tang et al., 2009, 2012). Moreover, there are many studies that use $\mathrm{HCHO} / \mathrm{NO}_{2}$ column ratio as an indicator to determine surface $\mathrm{O}_{3}-\mathrm{NO}_{x}-\mathrm{VOC}$ sensitivity in previous studies (Martin et al., 2004; Tang et al., 2012; Mahajan et al., 2015). However, there is a lack of observation for $\mathrm{NO}_{x}$ and $\mathrm{HCHO}$ vertical distribution in order to investigate the $\mathrm{O}_{3}$ formation and atmospheric chemistry in the lower troposphere. Modeling studies of boundary layer ozone over northern China show different sensitivity of ozone regime in the vertical, which is also impacted by the vertical circulation (Tang et al., 2017a, b). In addition, aerosols, particularly fine particles, are one of the major air pollutants in China. They play a key role in the Earth's climate and weather system. The chemical and physical properties of aerosols are strongly dependent on their compositions and sources. Previous studies show that secondary inorganic aerosols (sulfate and nitrate) are the dominating composition of the fine particles in both northern and eastern China (i.e., Shanghai and Beijing) (Du et al., 2011; Zhu et al., 2016). Therefore, we focus on analyzing the sec- ondary formation process of aerosols and photochemical pollution in this study.

Multi-axis differential optical absorption spectroscopy (MAX-DOAS) is a passive remote sensing technique measuring spectra of scattered sunlight at different elevation angles. Combined with forward radiative transfer simulations, MAX-DOAS measurements can provide vertical distribution information about aerosol extinction and trace gas concentration in the lower troposphere (Hönninger and Platt, 2002; Bobrowski et al., 2003; Hönninger et al., 2004; Wagner et al., 2004; Wittrock et al., 2004; Platt and Stutz, 2008). In the past decade, ground-based MAX-DOAS has been widely used for atmospheric aerosol and trace gas measurements (Frieß et al., 2006; Irie et al., 2008; Li et al., 2010, 2013). MAX-DOAS measurements are often used to validate satellite observations of atmospheric trace gases, e.g., $\mathrm{NO}_{2}, \mathrm{SO}_{2}$ and $\mathrm{HCHO}$ (Irie et al., 2008; Kramer et al., 2008; Ma et al., 2013; Wang et al., 2017). Light detection and ranging (lidar) is an active remote sensing measurement technique providing the quantitative range-resolved aerosol parameters. Aerosol vertical distribution obtained from lidar measurements is useful for the validation of MAX-DOAS retrieval of aerosol extinction profiles (Irie et al., 2008; Lee et al., 2011). Advanced lidar systems can also provide vertical profiles of different atmospheric species, such as ozone and water vapor.

Shanghai is one of the four directly controlled municipalities in China, with a population of over 24 million. Owing to the rapid urbanization of Shanghai and its surrounding cities in the Yangtze River Delta (YRD) region, air quality has deteriorated and become much more concerning, attracting more attention from the public and the scientific community (Geng et al., 2007; Chan et al., 2015). Shanghai has a large number of vehicles in China. Vehicle emissions were reported to contribute about $35 \%$ of the overall $\mathrm{NO}_{x}$ emission in Shanghai (Li et al., 2011; Hao et al., 2011). Fengxian, where the experiment was performed, is one of the subdistricts of Shanghai (see Fig. S1 in the Supplement) located in the north of Hangzhou Bay. The measurement site is mainly surrounded by agricultural area with only a few industrial and traffic emissions. During the measurement campaign, this area was mainly affected by the East Asian Monsoon, with prevailing winds being mainly southeasterly. A previous study shows that ozone pollution is particularly serious in rural areas of Shanghai during summer. Biogenic VOCs were found to be one of the major ozone precursors near the ground surface (Geng et al., 2007). However, there is a lack of observations for the investigation of the vertical ozone formation.

In this paper, we present the MAX-DOAS and lidar measurements for the vertical distribution of aerosol and trace gases in Fengxian during May 2016. The vertical profiles of aerosol and $\mathrm{NO}_{2}$ were retrieved and also validated by balloon-based measurements. Vertical distributions of $\mathrm{NO}_{2}$ and $\mathrm{HCHO}$, as well as an ozone profile, were used to investigate the ozone formation. In addition, horizontal and vertical 
fluxes of ozone were calculated from WRF-Chem simulations to estimate the ozone production at different altitudes.

\section{Measurements and methodology}

\subsection{The MAX-DOAS measurements}

The MAX-DOAS instrument operated at the measurement site in Fengxian consists of a telescope, two spectrometers with temperature stabilized at $20^{\circ}$ and a computer acting as the controlling and data acquisition unit. The viewing elevation angle of the telescope is controlled by a stepping motor. Scattered sunlight collected by the telescope is redirected by a prism reflector and quartz fibers to the spectrometer for spectral analysis. Two spectrometers (Ocean Optics HR2000+ and a Maya2000 Pro spectrometer) were used to cover both the UV (303-370 nm) and visible (390-608 nm) wavelength ranges. The full-width half-maximum (FWHM) spectral resolution of the UV and visible spectrometers is 0.5 and $0.3 \mathrm{~nm}$, respectively. The field of view (FOV) of the instrument is estimated to be less than $1^{\circ}$.

During the measurement period, the viewing azimuth direction was adjusted to the north. A full measurement sequence consists of seven elevation angles, i.e., 3, 5, 8, 10, 15,30 and $90^{\circ}$, each with 100 scans. The exposure time is automatically adjusted according to the intensity of the received scattered sunlight in order to achieve similar intensities for each elevation. The full measurement sequence takes about 5-15 min depending on the scattered sunlight intensity. Dark current and offset spectra were measured by blocking incoming light using a mechanical shutter and were subtracted from the measurement spectra before spectral analysis. In this study, data measured with a solar zenith angle (SZA) of less than $75^{\circ}$ were used to avoid strong influence from the stratospheric absorbers (Wang et al., 2014, 2017).

\subsubsection{Spectral analysis}

The spectra measured with MAX-DOAS were analyzed using the software QDOAS, which was developed by BIRAIASB (http://uv-vis.aeronomie.be/software/QDOAS/). The DOAS fit results are the differential slant column densities (DSCDs), i.e., the difference of the slant column density (SCD) between the off-zenith spectrum and the corresponding zenith reference spectrum. Details of the DOAS fit settings are listed in Table 1. A typical DOAS retrieval example for the oxygen dimer $\left(\mathrm{O}_{4}\right), \mathrm{NO}_{2}$ and $\mathrm{HCHO}$ is shown in Fig. S2. The stratospheric contribution was approximately eliminated by taking the zenith spectra of each scan as reference in the DOAS analysis. Before profile retrieval, DOAS fit results with a root mean square (RMS) of residuals larger than 0.003 were filtered.

\subsubsection{HEIPRO algorithm description and retrieval parameter settings}

Aerosol and trace gas (i.e., $\mathrm{NO}_{2}, \mathrm{HCHO}$ ) vertical profiles are retrieved from MAX-DOAS measurements using the HEIPRO (Heidelberg Profile, developed by IUP Heidelberg) retrieval algorithm (Frieß et al., 2006, 2011). The inversion algorithm is developed based on the optical estimation method (OEM) (Rodgers, 2000), which employs the radiative transfer model SCIATRAN as the forward model. In general, the maximum a posteriori (MAP) solution $\hat{x}$ is determined by minimizing the cost function $\chi^{2}$ (Frieß et al., 2006, 2011, 2016), which can be express as

$$
\begin{aligned}
\chi^{2}(x) & =[y-F(x, b)]^{T} S_{\in}^{-1}[y-F(x, b)] \\
& +\left[x-x_{\mathrm{a}}\right]^{T} S_{\mathrm{a}}^{-1}\left[x-x_{\mathrm{a}}\right] .
\end{aligned}
$$

The radiative transfer model or forward model $F(x, b)$ describes the measurement vector $\boldsymbol{y}$ (DSCDs at different elevation angles) as a function of the atmospheric state $\boldsymbol{x}$ (aerosol or trace gas profiles) and meteorological parameter $\boldsymbol{b}$ (i.e., pressure, temperature). The employed atmospheric pressure and temperature profiles were adapted from a climatology database, which contains various monthly and latitudinaldependent trace gas vertical profiles (Clémer et al., 2010; Hendrick et al., 2014; Wang et al., 2014, 2016).

We assume a fixed set of aerosol optical properties with an asymmetry parameter of 0.69 , a single-scattering albedo of 0.90 and a ground albedo of 0.05 . These values are considered realistic for Shanghai according to some measurements or previous studies (i.e., Chan et al., 2015). The lowest $4.0 \mathrm{~km}$ of the troposphere were divided into 20 layers, each with a thickness of $200 \mathrm{~m}$. A fixed temporal interval of 15 min was used in the inversion, which can cover at least one full scan sequence and include all the measured DSCDs during this period. $x_{\mathrm{a}}$ denotes the a priori state vector serving as an additional constraint in the optimization. In order to investigate the impacts of an a priori profile shape on the aerosol inversion, four different a priori extinction profiles available in the HEIPRO algorithm, i.e., linearly decreasing, exponentially decreasing, Boltzmann distribution (smoothed box-shaped) and Gaussian distribution (peaking shape), were used for the sensitivity study (Wang et al., 2016). Details of the sensitivity study are presented in Sect. 3.1. For $\mathrm{NO}_{2}$ and $\mathrm{HCHO}$ retrieval, both the a priori profile $x_{\mathrm{a}}$ values are exponentially decreasing with a scaling height of $3 \mathrm{~km}$, in which the surface concentration of $\mathrm{NO}_{2}$ and $\mathrm{HCHO}$ is set to 10.5 and $1.5 \mathrm{ppb}$, respectively.

The covariance matrixes $\mathbf{S}_{\mathrm{a}}$ and $\mathbf{S}_{\in}$ describe the uncertainties and the cross correlation between different layers in the a priori and between measurements at different elevation angles, respectively. Another important quantity is the Jacobian matrix $\mathbf{A}=\partial \hat{x} / \partial x$. It represents the sensitivity of the retrieval to the true state. In addition, $\mathbf{A}$ provides the degree 
Table 1. Setting for the $\mathrm{O}_{4}, \mathrm{NO}_{2}$ and $\mathrm{HCHO}$ DOAS spectral analyses.

\begin{tabular}{|c|c|c|c|c|}
\hline \multirow[t]{2}{*}{ Parameter } & \multirow[t]{2}{*}{ Data source } & \multicolumn{3}{|c|}{ Fitting interval } \\
\hline & & $\mathrm{O}_{4}$ & $\mathrm{NO}_{2}$ & $\mathrm{HCHO}$ \\
\hline Wavelength range & & $425-490 \mathrm{~nm}$ & $425-490 \mathrm{~nm}$ & $336.5-359 \mathrm{~nm}$ \\
\hline $\mathrm{NO}_{2}$ & $\begin{array}{l}298 \mathrm{~K}, I_{0} * \text { correction ( } \mathrm{SCD} \text { of } 10^{17} \text { molecules } \mathrm{cm}^{-2} \text { ); } \\
\text { Vandaele et al. (1998) }\end{array}$ & $\sqrt{ }$ & $\sqrt{ }$ & $\sqrt{ }$ \\
\hline $\mathrm{NO}_{2}$ & $\begin{array}{l}220 \mathrm{~K}, I_{0} \text { correction (SCD of } 10^{17} \text { molecules } \mathrm{cm}^{-2} \text { ), } \\
\text { pre-orthogonalized; Vandaeele et al. (1998) }\end{array}$ & $\sqrt{ }$ & $\sqrt{ }$ & $\times$ \\
\hline $\mathrm{O}_{3}$ & $\begin{array}{l}223 \mathrm{~K}, I_{0} \text { correction (SCD of } 10^{20} \text { molecules } \mathrm{cm}^{-2} \text { ); } \\
\text { Serdyuchenko et al. }(2014)\end{array}$ & $\sqrt{ }$ & $\sqrt{ }$ & $\sqrt{ }$ \\
\hline $\mathrm{O}_{3}$ & $\begin{array}{l}243 \mathrm{~K}, I_{0} \text { correction }\left(\mathrm{SCD} \text { of } 10^{20} \text { molecules } \mathrm{cm}^{-2} \text { ), }\right. \\
\text { pre-orthogonalized; Serdyuchenko et al. }(2014)\end{array}$ & $x$ & $\sqrt{ }$ & $\sqrt{ }$ \\
\hline $\mathrm{O}_{4}$ & 293 K; Thalman and Volkamer (2013) & $\sqrt{ }$ & $\sqrt{ }$ & $\sqrt{ }$ \\
\hline $\mathrm{HCHO}$ & $297 \mathrm{~K}$; Meller and Moortgat (2000) & $x$ & $\sqrt{ }$ & $x$ \\
\hline $\mathrm{BrO}$ & 223 K; Fleischmann et al. (2004) & $x$ & $x$ & $\sqrt{ }$ \\
\hline $\mathrm{H}_{2} \mathrm{O}$ & 296 K, HITEMP; Rothman et al. (2010) & $\sqrt{ }$ & $\sqrt{ }$ & $x$ \\
\hline Ring & Calculated with QDOAS & $\sqrt{ }$ & $\sqrt{ }$ & $\sqrt{ }$ \\
\hline Polynomial degree & & Order 5 & Order 5 & Order 5 \\
\hline Intensity offset & & Constant & Constant & Constant \\
\hline
\end{tabular}

* Solar $I_{0}$ correction; Aliwell et al. (2002).

of freedom of signal (DFS), corresponding to the number of independent pieces contained in the measurement.

\subsection{Lidar measurements}

A polarization backscatter lidar was installed at the same experiment site collocating with the MAX-DOAS instrument. The lidar system is equipped with a diode-pumped Nd:YAG laser emitting laser pulses at 532 and $355 \mathrm{~nm}$ by doubling and tripling the laser frequency. The typical pulse energy of the laser is about $20 \mathrm{~mJ}$ with a pulse repetition frequency of $20 \mathrm{~Hz}$. The laser beam is emitted with a divergence of $0.25 \mathrm{mrad}$ and $158 \mathrm{~mm}$ off-axis to the receiving telescope with a FOV of $0.5 \mathrm{mrad}$, resulting in an overlap height of about $195 \mathrm{~m}$. A constant lidar ratio $\left(S_{p}\right.$, extinctionto-backscatter ratio) of $50 \mathrm{sr}$ was assumed in the lidar retrieval.

Another ozone lidar was applied to detect the $\mathrm{O}_{3}$ profiles at the same time. The differential absorption lidar system emits a laser pulse at $316 \mathrm{~nm}$. The typical pulse energy of the laser is about $90 \mathrm{~mJ}$ with a pulse repetition frequency of $10 \mathrm{~Hz}$. The laser beam is emitted with a divergence of $0.3 \mathrm{mrad}$ and $120 \mathrm{~mm}$ off-axis to the receiving telescope with a FOV of $0.5 \mathrm{mrad}$, resulting in an overlap height of about $300 \mathrm{~m}$.

\subsection{Ancillary data}

Vehicle-based tethered-balloon observations were also preformed regularly at the measurement site during the campaign. The balloon measurement provides information of several meteorological parameters, including temperature, pressure, relative humidity, wind speed and atmospheric pol- lutants, i.e., $\mathrm{PM}_{2.5}, \mathrm{PM}_{10}, \mathrm{NO}_{2}$ and $\mathrm{O}_{3}$, from ground level up to $900 \mathrm{~m}$ above ground level ( $\mathrm{Li}$ et al., 2015). The $\mathrm{O}_{3}$ concentrations were measured by a UV photometric analyzer (Thermo 49i, Thermo Fisher, USA). $\mathrm{NO}_{2}$ concentrations were obtained from a nitrogen oxide analyzer (Thermo 42i, Thermo Fisher, USA). Moreover, particulate matter ( $\mathrm{PM}_{2.5}$ and $\mathrm{PM}_{10}$ ) concentrations were measured with the tapered element oscillating microbalance (TEOM) online particle monitors (Thermo TEOM 1405, Thermo Fisher, USA).

In addition, a dynamical-chemical model (WRF-Chem) was used to study the temporal development and the formation of ozone. A detailed description of the model can be found in Grell et al. (2005). The simulation domain was set to cover an area of $1200 \times 1200 \mathrm{~km}^{2}\left(114-127^{\circ} \mathrm{E}, 25-36^{\circ} \mathrm{N}\right)$ in order to include a number of large cities in the YRD area. The horizontal resolution of the simulation is set to $12 \times 12 \mathrm{~km}^{2}$ while vertical direction of the model is divided into 26 hybrid pressure-sigma levels extending from the ground up to $17 \mathrm{~km}$. This setting allows a better reconstruction of the atmospheric status and less impacts due to the diverse emissions of these cities.

\section{Results and discussion}

\subsection{Dependence of retrieval on an a priori profile}

The inversion of aerosol extinction profiles was achieved by fitting the $\mathrm{O}_{4}$ DSCD measurements to the forward model simulations. Previous studies show that there is a systematic uncertainty on the $\mathrm{O}_{4}$ absorption, in which the uncertainty of the $\mathrm{O}_{4}$ absorption was estimated to be $\sim 25 \%$ (Clémer 

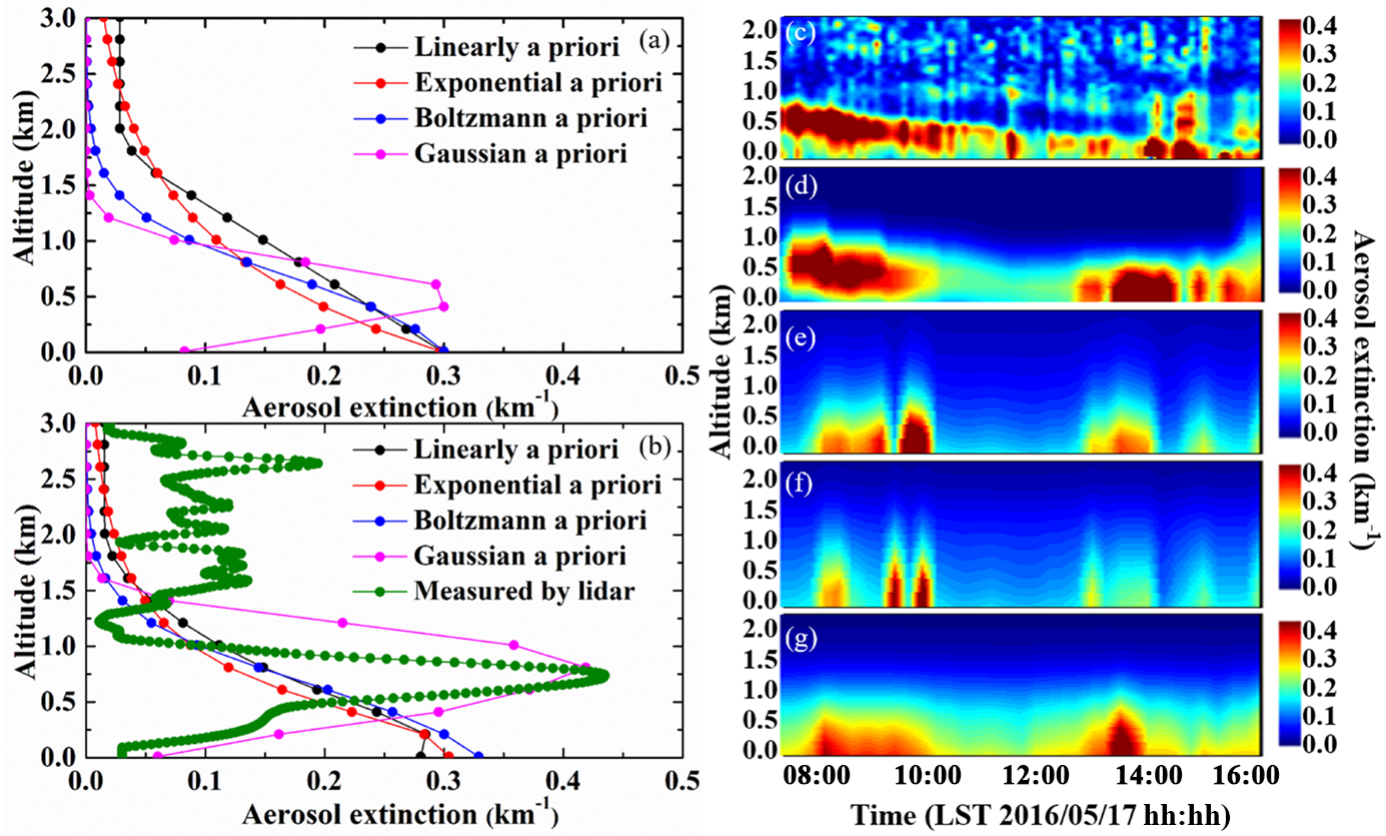

Figure 1. Different a priori and corresponding aerosol extinction retrievals on 17 May 2016. (a) Different a priori aerosol extinction profiles used in HEIPRO. Panel (b) shows four kinds of retrieved aerosol profiles and the lidar-measured profile at 8:30. Diurnal aerosol extinction coefficient at $477 \mathrm{~nm}$ from (c) Mie-scattering polarization lidar and retrieved using different a priori (d) Gaussian, (e) exponential, (f) linear and (g) Boltzmann distributions.

et al., 2010; Großmann et al., 2013; Vlemmix et al., 2015). However, the reason for the uncertainty is not yet well understood. The uncertainty is typically corrected by multiplying the $\mathrm{O}_{4}$ absorption cross section with a constant correction factor (Wagner et al., 2009, 2011; Clémer et al., 2010; Chan et al., 2015; Wang et al., 2016). By comparing the measured and modeled $\mathrm{O}_{4}$ absorptions, we estimated that the literature $\mathrm{O}_{4}$ absorption cross section was underestimated by $20 \%$. Therefore, a scaling factor of 1.2 was selected to multiply with the $\mathrm{O}_{4}$ cross section for the $\mathrm{O}_{4}$ retrieval band between 425 and $470 \mathrm{~nm}$.

In order to investigate the impacts of different a priori profile on aerosol retrieval, a cloud-free day of 17 May 2016 was selected for the aerosol a priori sensitivity study. Figure 1a shows the available a priori aerosol configuration profile in the HEIPRO algorithm, including linear, exponential, Boltzmann and Gaussian shapes. The corresponding retrieved aerosol extinction profile is shown in Fig. $1 \mathrm{~b}$ together with lidar observation. The retrieval results using linear, exponential and Boltzmann a priori aerosol profiles are very similar, displaying the maximum aerosol extinction close to the ground. The aerosol extinction profile retrieved using the Gaussian a priori profile shows the best agreement with simultaneous lidar measurements exhibiting an elevated layer during this period. Furthermore, the diurnal aerosol extinction profiles retrieved with different a priori profile and the lidar measurements are shown in the right panel of Fig. 1. The retrieval with the Gaussian a priori profile also shows a better consistency with lidar results during the whole day. The in situ measurements of particle mass concentrations can also be used to semiquantitatively validate the MAXDOAS retrieval of aerosol extinction coefficients (Wang et al., 2016). We compared the retrieved aerosol extinction profiles to the balloon-based $\mathrm{PM}_{2.5}$ measurements. As shown in Fig. S3a, the aerosol profile retrieved using Gaussian a priori profile shows the best agreement with the balloonbased measurements; both measurements show a peak value at about $0.75 \mathrm{~km}$ above ground level.

Table 2 summarized the parameters of aerosol retrieval performance on 17 May 2016. The retrieval errors and resulting cost functions using Gaussian a priori profile are the smallest among all a priori profiles. Moreover, the DFS is about 2.96 when a Gaussian a priori was used. The DFS value suggests that at least two independent pieces of information can be determined from the measurements. Thus, the sensitivity study indicates that the Gaussian a priori profile is the most realistic option for aerosol retrieval during this campaign. As a consequence, the Gaussian aerosol profile is selected as the a priori profile for all aerosol retrievals in this study.

In addition, aerosols strongly influence the effective light path of scattered sunlight in the atmosphere and the SCDs of trace gases. Therefore, we have examined the sensitivity of trace gas retrieval to aerosol profiles. Aerosol profiles retrieved with different a priori profile shapes were used in the differential air mass factor $(\triangle \mathrm{AMF})$ calculation 
Table 2. Cost function, DFS and retrieved errors using different a priori profiles in the aerosol retrieval on 17 May 2016.

\begin{tabular}{lcrrrr}
\hline The shape of the a priori profile & Chi square & DFS & $\begin{array}{r}\text { Retrieved error } \\
(<5 \%)\end{array}$ & $\begin{array}{r}\text { Smooth error } \\
(<5 \%)\end{array}$ & $\begin{array}{r}\text { Noise error } \\
(<5 \%)\end{array}$ \\
\hline Linearly shape & 48.534512 & 2.957806 & $65 \%$ & $65 \%$ & $100 \%$ \\
Exponential shape & 22.907515 & 2.9162457 & $75 \%$ & $75 \%$ & $100 \%$ \\
Boltzmann shape & 28.533862 & 3.0331712 & $65 \%$ & $65 \%$ & $80 \%$ \\
Gaussian shape & 2.9297998 & 2.9614936 & $100 \%$ & $100 \%$ & $100 \%$ \\
\hline
\end{tabular}

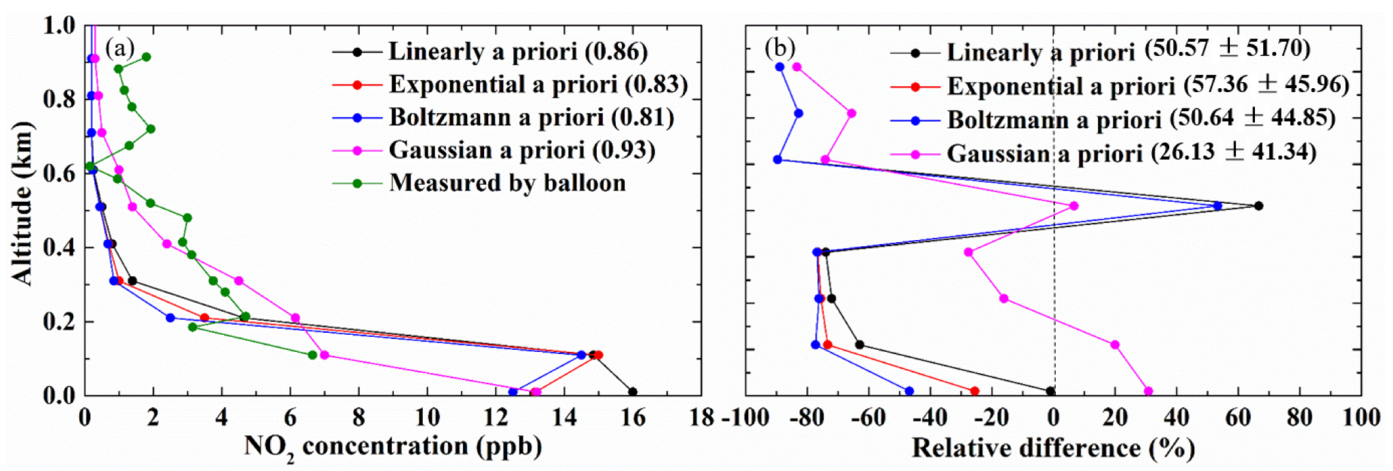

Figure 2. Comparison of $\mathrm{NO}_{2}$ profiles retrieved using four different aerosol a priori profiles as inputs and measured using a tethered balloon. Panel (a) shows the four retrieved vertical $\mathrm{NO}_{2}$ concentrations and balloon-based measurement, as well as the correlation coefficients shown in the brackets. Panel (b) shows the mean differences and standard deviations in the brackets between four different retrieved $\mathrm{NO}_{2}$ profiles and the balloon-based $\mathrm{NO}_{2}$ profiles.

for the $\mathrm{NO}_{2}$ profile retrieval in the visible band of 425 to $470 \mathrm{~nm}$. $\mathrm{NO}_{2}$ profiles retrieved with different aerosol profiles are shown in Fig. 2a. The results show that the retrieved vertical distributions of $\mathrm{NO}_{2}$ are easily impacted by the aerosol vertical distributions introduced. The $\mathrm{NO}_{2}$ profile retrieved by the Gaussian aerosol a priori profile is significantly different from the others. Using balloon-based measurements as a reference, the $\mathrm{NO}_{2}$ profile retrieved with the Gaussian aerosol a priori profile shows the best agreement. For the other three retrievals, $\mathrm{NO}_{2}$ concentrations at the upper layers are significantly lower than the balloon measurement. Moreover, the $\mathrm{NO}_{2}$ profile retrieved using a Gaussian aerosol a priori profile as input is correlated better $(R=0.93)$ with balloon-based $\mathrm{NO}_{2}$ concentration profiles than others. In Fig. 2b, the mean difference and standard deviations between the $\mathrm{NO}_{2}$ profile retrieved using a Gaussian aerosol a priori profile as input and balloon-based measured $\mathrm{NO}_{2}$ profile $(26.14 \% \pm 41.34 \%)$ is smaller than the other three retrieved $\mathrm{NO}_{2}$ profiles. All these results indicate that aerosol profile scenarios are very important for the trace gas retrieval.

\subsection{Temporal variations in $\mathrm{NO}_{2}$}

Time series of $\mathrm{NO}_{2}$ concentration profiles were retrieved from MAX-DOAS measurement using the HEIPRO algorithm. In order to convert the $\mathrm{NO}_{2} \mathrm{SCDs}$ to tropospheric vertical column densities (VCDs), $\mathrm{NO}_{2}$ profiles retrieved with MAX-DOAS, lidar aerosol profiles, and averaged tempera- ture and pressure profiles measured using in situ instruments on the balloon were introduced as inputs in the radiative transfer model for the $\mathrm{NO}_{2}$ air mass factor (AMF) calculation. Figure 3 shows the temporal variations in hourly averaged tropospheric $\mathrm{NO}_{2}$ VCDs and vertical profiles. During the measurement campaign, significant $\mathrm{NO}_{2} \mathrm{VCD}$ peaks were observed on 10 and 16 May 2016. By extracting $\mathrm{NO}_{2}$ concentration at the lowest layer of the retrieval, the averaged ground-level $\mathrm{NO}_{2}$ mixing ratio of $12.4 \mathrm{ppb}$ in the Fengxian area is generally much lower than that in the city center of Shanghai (63.3 ppb) (available from http://www.semc. gov.cn/aqi/home/Index.aspx). The sectoral $\mathrm{NO}_{x}$ emissions in the Fengxian area can be divided into three major types, i.e., transportation, industrial + residential and power generation. These three emission sources contributed $83 \%$ (transportation), $15 \%$ (industrial + residential) and $2 \%$ (power generation) of the total $\mathrm{NO}_{x}$ emissions in Fengxian (Chan et al., 2015). The emission inventory indicates that transportation emission plays a dominant role in the local $\mathrm{NO}_{x}$ concentration. To assess the role of air mass transport during the $\mathrm{NO}_{2}$ episode periods, $24 \mathrm{~h}$ air mass backward trajectories (AMBTs) from 08:00 to 17:00 LST (local standard time) at an altitude of $500 \mathrm{~m}$ over the experimental site were calculated. As shown in Fig. S4, the peak values of tropospheric $\mathrm{NO}_{2}$ VCDs are closely related to the wind direction. Increased $\mathrm{NO}_{2}$ levels mainly occurred during northwesterly or northerly wind conditions, especially during the 


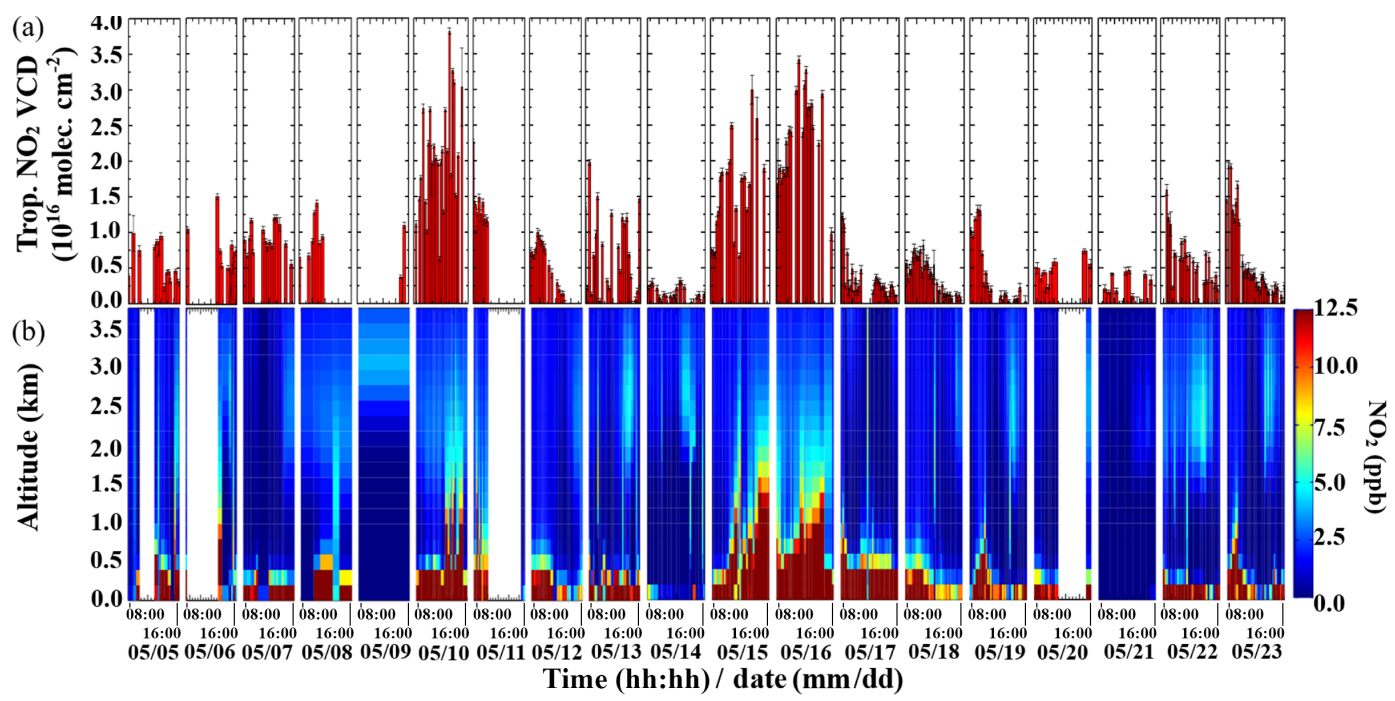

Figure 3. Time series of hourly averaged (a) $\mathrm{NO}_{2}$ VCDs and (b) $\mathrm{NO}_{2}$ vertical profiles from MAX-DOAS measurements.

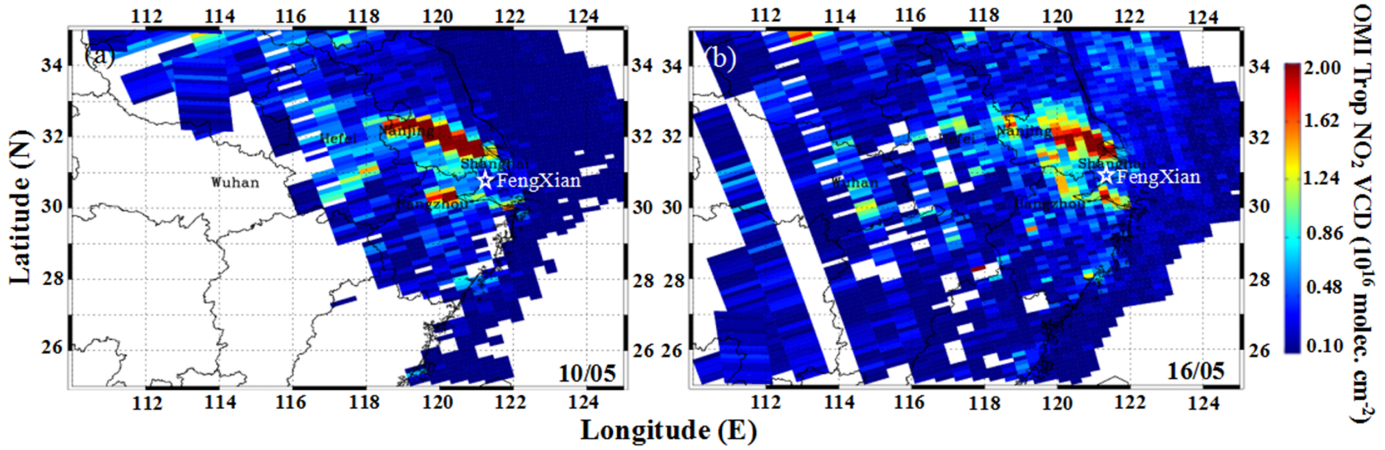

Figure 4. Spatial distribution of USTC OMI tropospheric $\mathrm{NO}_{2}$ VCDs on (a) 10 and (b) 16 May 2016.

episodes on 10 and 16 May. Transportation of $\mathrm{NO}_{2}$ can also be observed from OMI satellite measurements during these episode days. Figure 4 shows the spatial distribution of tropospheric $\mathrm{NO}_{2}$ VCDs from USTC (University of Science and Technology of China) OMI products on 10 and 16 May. Major industrial areas such as Baoshan, Jiading, the northern part of Pudong district in Shanghai and a heavy industrial city (i.e., Zhangjiagang) are located along the backward trajectories during the $\mathrm{NO}_{2}$ episode days. In contrast, lowertropospheric $\mathrm{NO}_{2} \mathrm{VCDs}$ were observed during southerly and easterly wind conditions in which the air masses were coming from unpolluted regions and the East China Sea.

The MAX-DOAS $\mathrm{NO}_{2}$ measurements are also used to validate the USTC OMI $\mathrm{NO}_{2}$ product (Liu et al., 2016). MAXDOAS $\mathrm{NO}_{2}$ VCDs were temporally averaged over the OMI overpass time of 12:00 to 13:00 LST, while the OMI $\mathrm{NO}_{2}$ data are spatially averaged over pixels within $15 \mathrm{~km}$ of the experimental site. Previous study shows that a better approximation of trace gas and aerosol profiles for the tropospheric AMF calculation can significantly improve the $\mathrm{OMI} \mathrm{NO}_{2}$
VCDs over the polluted area by $35-40 \%$ and bring them closer to the ground-based observations (Lin et al., 2014). Therefore, we have recomputed the $\mathrm{OMI} \mathrm{NO}$ tropospheric AMFs by using the combined $\mathrm{NO}_{2}$ profiles, in which the lowest $3 \mathrm{~km}$ was adopted from the MAX-DOAS $\mathrm{NO}_{2}$ profile retrieval, while $\mathrm{NO}_{2}$ profiles above $3 \mathrm{~km}$ were taken from WRF-Chem simulations. Daily tropospheric $\mathrm{NO}_{2} \mathrm{VCDs}$ from MAX-DOAS measurement, NASA and the USTC OMI product are shown in Fig. 5a. The temporal trends in MAXDOAS and USTC OMI data show similar characteristics. However, the MAX-DOAS measurements are systematically higher than OMI observations by $23 \%$ on average. These discrepancies can be explained by the averaging effect over the large OMI pixel, which includes the neighboring clean areas. The correlations between MAX-DOAS and two different OMI products are shown in Fig. 5b. The USTC OMI products agree better with the MAX-DOAS observations, with a Pearson correlation coefficient $(R)$ of 0.95 (slope of 0.74 and offset of $-2.09 \times 10^{15} \mathrm{molec} \mathrm{cm}^{-2}$ ), while the correlation between MAX-DOAS and the NASA OMI product is 0.71 , 

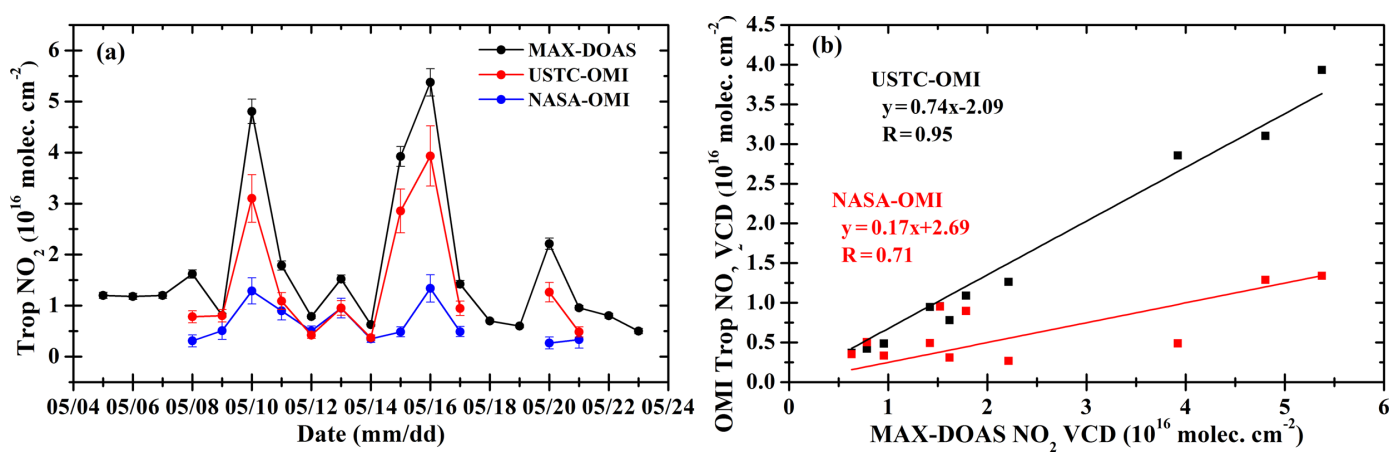

Figure 5. Comparison of tropospheric $\mathrm{NO}_{2}$ VCDs between ground-based MAX-DOAS measurement and OMI satellite observation. Panel (a) shows time series of daily averaged tropospheric $\mathrm{NO}_{2}$ VCDs. MAX-DOAS data are averaged around the OMI overpass time. Panel (b) shows the correlation of daily averaged tropospheric $\mathrm{NO}_{2}$ VCDs measured by MAX-DOAS with USTC OMI and NASA OMI satellite data. The OMI measurements are spatially averaged over the grid cells within $15 \mathrm{~km}$ of ground location around the campaign site.

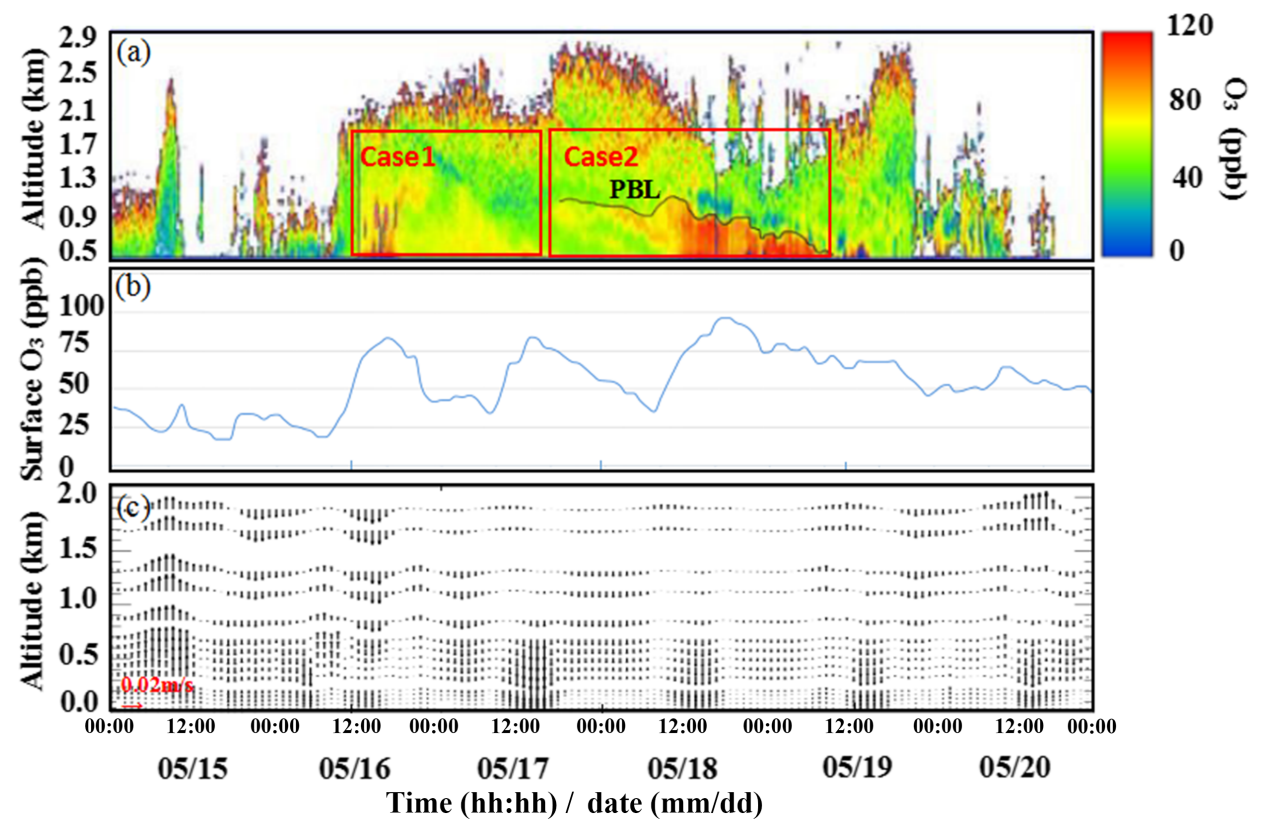

Figure 6. Time series of (a) ozone vertical distributions measured by ozone lidar, (b) surface $\mathrm{O}_{3}$ concentrations detected from the in situ ozone instrument and (c) vertical wind profiles simulated by WRF in Fengxian from 15 to 20 May 2016.

with a slope of 0.17 and an offset of $2.69 \times 10^{15}$ molec $^{-2}$. Compared to MAX-DOAS measurements and USTC OMI products, the NASA OMI $\mathrm{NO}_{2}$ products report much lower $\mathrm{NO}_{2}$ VCDs, especially during these two $\mathrm{NO}_{2}$ episode days. The results suggest that adopting local measurements of atmospheric parameters, i.e., aerosols and trace gas profiles, in AMF calculation could improve the accuracy of satellite VCD products.

\subsection{Ozone vertical distribution}

Enhanced surface $\mathrm{O}_{3}$ concentrations were found over rural areas of Shanghai compared to the city center (Geng et al., 2008; Xing et al., 2011). This probably resulted from the sig- nificant contribution of anthropogenic emissions of $\mathrm{NO}$ in the city center, which consumes ambient ozone through NO titration (i.e., $\mathrm{NO}+\mathrm{O}_{3} \rightarrow \mathrm{NO}_{2}+\mathrm{O}_{2}$ ). In this study, we focused on the formation pathways and the vertical distribution of $\mathrm{O}_{3}$ in rural areas. In order to validate the vertical ozone distribution from lidar measurements, ozone profiles were compared to simultaneous ozone balloon-based measurements. The comparison results show a good agreement with each other (see Fig. S3b-d). Time series of ozone vertical distributions measured by the lidar and surface ozone concentrations measured by the in situ monitor are shown in Fig. 6a and $b$, respectively. The measurement results show significantly lower ozone concentrations on 15 and 20 May 2016. Meteorological data show that the solar irradiance was rela- 
Table 3. Statistical analysis for the simulation of wind speed and ozone concentrations at different altitudes.

\begin{tabular}{lrrrrr}
\hline & Altitudes (m) & RMSE & RMSEs & RMSEu & $d$ \\
\hline Wind speed $\left(\mathrm{m} \mathrm{s}^{-1}\right)$ & 580 & 0.61 & 0.31 & 0.49 & 0.83 \\
& 670 & 0.58 & 0.28 & 0.53 & 0.69 \\
& 800 & 0.70 & 0.40 & 0.59 & 0.79 \\
\hline Ozone (ppbv) & 580 & 6.6 & 3.2 & 6.5 & 0.63 \\
& 670 & 8.1 & 4.1 & 7.0 & 0.57 \\
& 800 & 7.3 & 3.7 & 6.7 & 0.59 \\
\hline
\end{tabular}

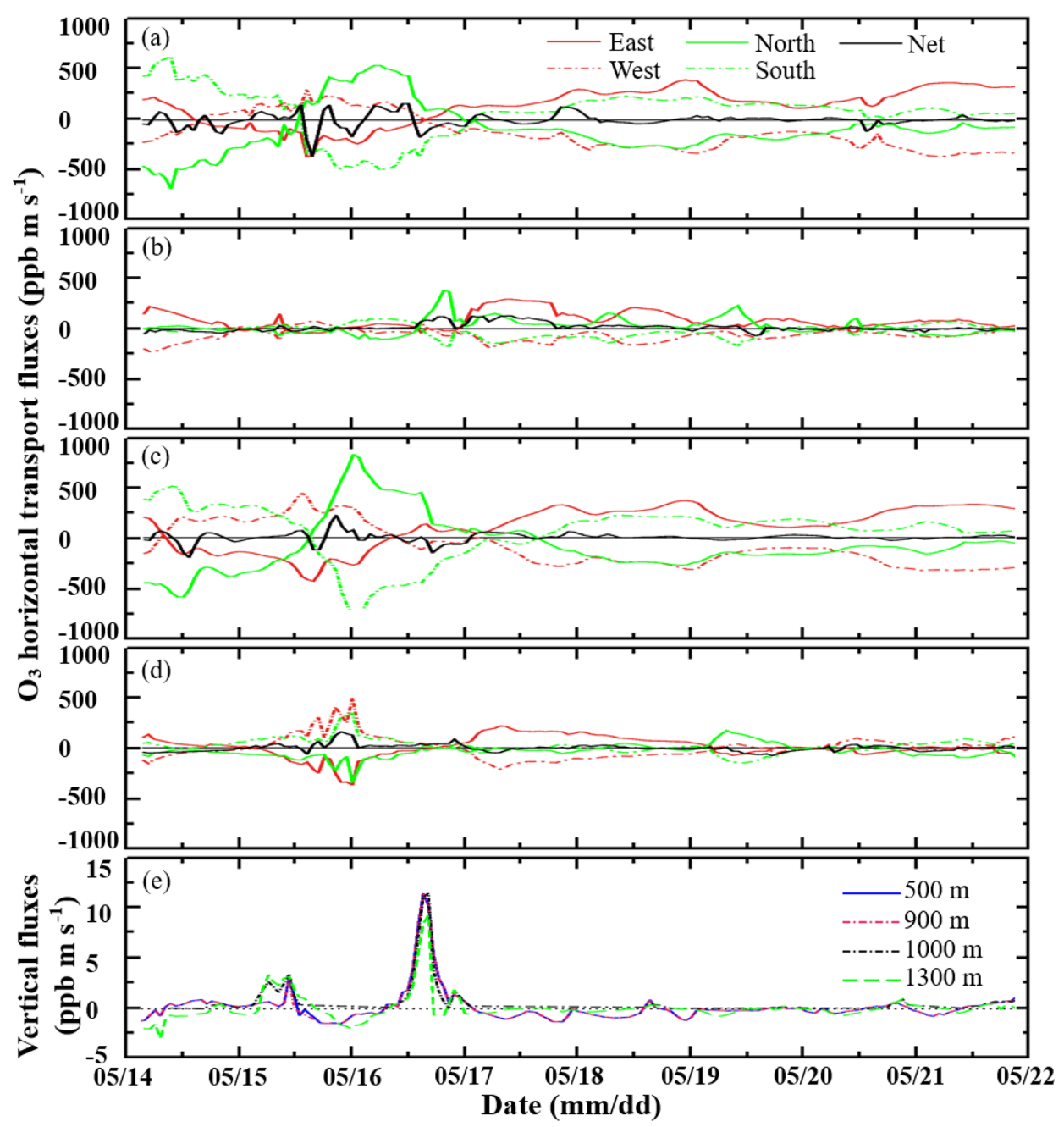

Figure 7. Ozone horizontal transport fluxes at (a) $500 \mathrm{~m}$, (b) $900 \mathrm{~m}$, (c) $1000 \mathrm{~m}$ and (d) $1300 \mathrm{~m}$, as well as (e) vertical transport fluxes.

tively low and associated with occasional rain on these two days. Decreases in ozone concentration were probably due to lower solar irradiance affecting the photochemical formation of ozone and rainy condition favoring the wet removal pathway of atmospheric ozone. High ozone concentrations were observed at noontime (12:00-14:00) on 16 and 17 May (case 1) as well as all day on 18 May (case 2).
For case 1 indicated in Fig. 6a, surface $\mathrm{O}_{3}$ concentrations measured by the in situ monitor correlated well with the lidar observations at low altitudes, particularly for peak ozone values of 75-80 ppb during these two periods. On 16 May, enhanced ozone values not only occurred at surface level but were also found at an altitude of about $1.1 \mathrm{~km}$. In contrast, high ozone concentrations were only found at surface level but there was no extension to the high altitudes during the 


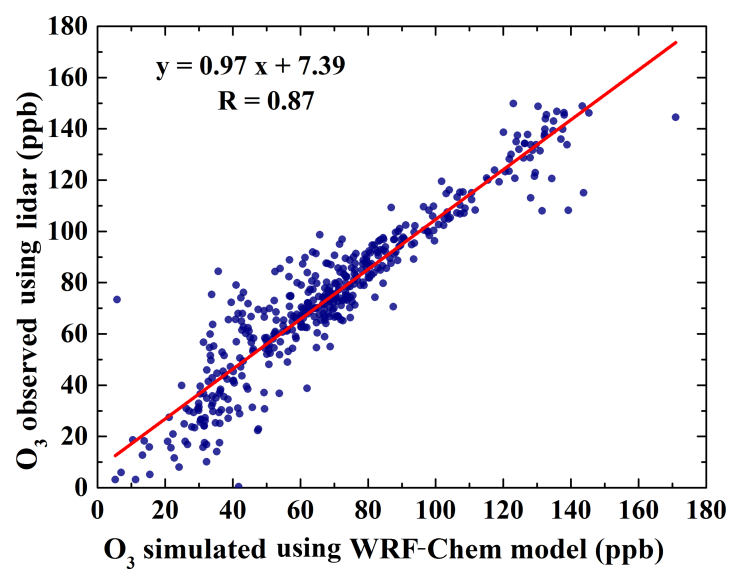

Figure 8. Correlation of $\mathrm{O}_{3}$ concentration at different altitudes between WRF-Chem simulation and lidar measurement.

same time period on 17 May. To further investigate the causes of enhanced $\mathrm{O}_{3}$ levels at upper altitudes on 16 May, we calculated the $\mathrm{O}_{3}$ fluxes in both the horizontal and vertical directions using WRF-Chem simulations (Jiang et al., 2008). The horizontal $\mathrm{O}_{3}$ fluxes calculated by multiplying the horizontal wind speed with the $\mathrm{O}_{3}$ concentration of the corresponding grid were illustrated in Fig. 7a to d. The vertical flux, shown in Fig. 7e, is defined as the product of vertical wind speed and $\mathrm{O}_{3}$ concentration at the corresponding layer. Positive values represent upward transportation. To evaluate the accuracy of model simulations, the simulated ozone concentrations were validated using the ozone lidar measurements. Figure 8 shows the correlation of $\mathrm{O}_{3}$ concentration between model simulation and lidar measurement from 0.3 to $1.5 \mathrm{~km}$. Both datasets agree well with each other, with a Pearson correlation coefficient $(R)$ of 0.87 (slope of 0.97 and offset of $7.39 \mathrm{ppb}$ ). In addition, the RMSE, root mean square error systematic (RMSEs), root mean square error unsystematic (RMSEu) and the index of agreement $(d)$ at different altitudes were analyzed to quantify the differences between the measured and simulated values (Willmott, 1981; Geng et al., 2007). A summary of the statistical analysis is listed in Table 3 . The results indicate that the model is able to reproduce the reality. The flux analysis in Fig. 7 shows that horizontal transportation at 900,1000 and $1300 \mathrm{~m}$ was trivial (2.1, 11.7 and $1.1 \mathrm{ppb} \mathrm{m} \mathrm{s}^{-1}$ averaged net values) between 12:00 and 14:00 on 16 May. The results indicate that the horizontal transportation values only show negligible effects on the enhanced ozone concentrations at upper altitudes during this time period. Since the vertical wind speed is relatively low ( $\sim 0.01 \mathrm{~m} \mathrm{~s}^{-1}$; in Fig. 6c), the vertical transportation values was considered only to play a minor role. Both the horizontal and vertical transportation were not significant; thus, enhanced ozone levels at upper altitudes were mainly due to local formation.

In case 2 , high $\mathrm{O}_{3}$ concentrations were observed from ground surface to higher altitudes on 18 May. Ozone was mainly concentrated at a layer of $0.9 \mathrm{~km}$ from 03:00 to 08:00 LST. Then the ozone layer began to disperse to adjacent layers from 0.5 to $1.3 \mathrm{~km}$. Furthermore, the ozone concentration gradually increased to more than $115 \mathrm{ppb}$ from 0.5 to $0.9 \mathrm{~km}$ after $12: 30$. Time series of the planetary boundary layer (PBL) height retrieved from the Mie lidar measurement is shown in Fig. 6a (He et al., 2006). It is found that the PBL is relatively stable (at about $0.9 \mathrm{~km}$ ) from 00:00 to 8:00 on 18 May. This suggests that the ozone layer was constrained above PBL height at that moment. Afterwards, the PBL height subsequently rose after sunrise due to the increase in air temperature. Owing to the rise of PBL height and the downward wind, ozone at upper altitudes was gradually mixed and spread throughout the PBL from 9:00 to $12: 30$. After 12:30, the horizontally averaged net flux of $\mathrm{O}_{3}$ at $500,900,1000$ and $1300 \mathrm{~m}$ was $-1.9,1.3,-0.44$ and $1.1 \mathrm{ppb} \mathrm{m} \mathrm{s}^{-1}$, respectively. The vertical wind speed at different altitudes is extremely low $\left(<0.005 \mathrm{~m} \mathrm{~s}^{-1}\right)$, resulting in the lower $\mathrm{O}_{3}$ vertical flux of $-1.2,-1.2,-0.08$ and $-0.13 \mathrm{ppb} \mathrm{m} \mathrm{s}^{-1}$ at these altitudes. The analysis above implies that the increased ozone in the PBL after 12:30 was probably related to local formation. More details about the gas chemical analysis during the promoting $\mathrm{O}_{3}$ formation were discussed in Sect. 3.4.

\section{$3.4 \mathrm{O}_{3}-\mathrm{NO}_{2}-\mathrm{HCHO}$ in vertical}

As discussed in Sect. 3.3, two high ozone concentration episodes were mainly locally formed. VOCs are the important precursors for the $\mathrm{O}_{3}$ formation in urban areas (Kleinman et al., 2001; Zhang et al., 2004; Geng et al., 2007). Previous studies show that the formation of surface $\mathrm{O}_{3}$ is mainly under a VOC-sensitive regime in Shanghai (Geng et al., 2008). The production of $\mathrm{O}_{3}$ is not only due to the abundance of VOCs but also related to the reactions with $\mathrm{OH}$ radicals and solar irradiance. As HCHO is one of the major VOCs and strongly correlated with peroxy radicals (Sillman, 1995; Duncan et al., 2010), HCHO measurement results were used as an indicator to represent the total VOCs here. Observations of $\mathrm{NO}_{x}$ and VOC vertical distribution can provide indispensable information to investigate the ozone formation pathways.

Vertical distributions of $\mathrm{NO}_{2}$ and $\mathrm{HCHO}$ were retrieved from the MAX-DOAS observations during the campaign. Figure 9 shows the time series of $\mathrm{NO}_{2}, \mathrm{HCHO}$ and $\mathrm{O}_{3}$ vertical distributions from 15 to 20 May. Missing data are due to cloud filtering and/or low signal-to-noise ratio of the measurements. The distribution patterns of $\mathrm{HCHO}$ and $\mathrm{O}_{3}$ above $500 \mathrm{~m}$ were very similar. However, $\mathrm{NO}_{2}$ was mainly concentrated below $500 \mathrm{~m}$. Here we focus on 18 May to investigate the causes of high ozone concentration. As discussed for case 2 in Sect. 3.3, it is found that both horizontal and vertical transportation contribution are trivial compared to the total $\mathrm{O}_{3}$ concentration observed on this day. Moreover, we found that the higher $\mathrm{HCHO}$ concentration ( $>8 \mathrm{ppb}$ ) occurred prior 


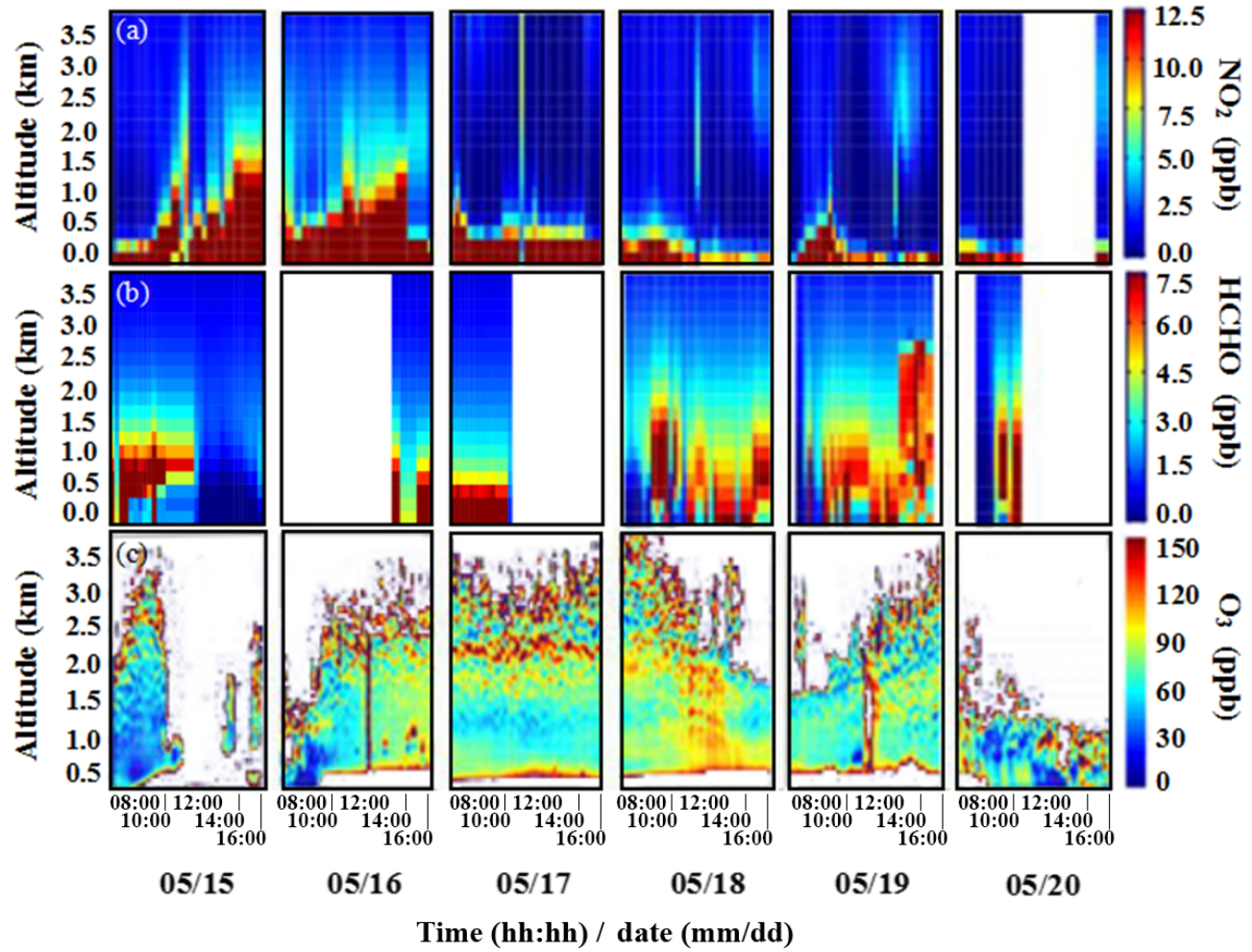

Figure 9. Time series of retrieved (a) $\mathrm{NO}_{2}$ and (b) $\mathrm{HCHO}$ vertical profiles from MAX-DOAS, as well as (c) $\mathrm{O}_{3}$ vertical profiles measured using lidar.

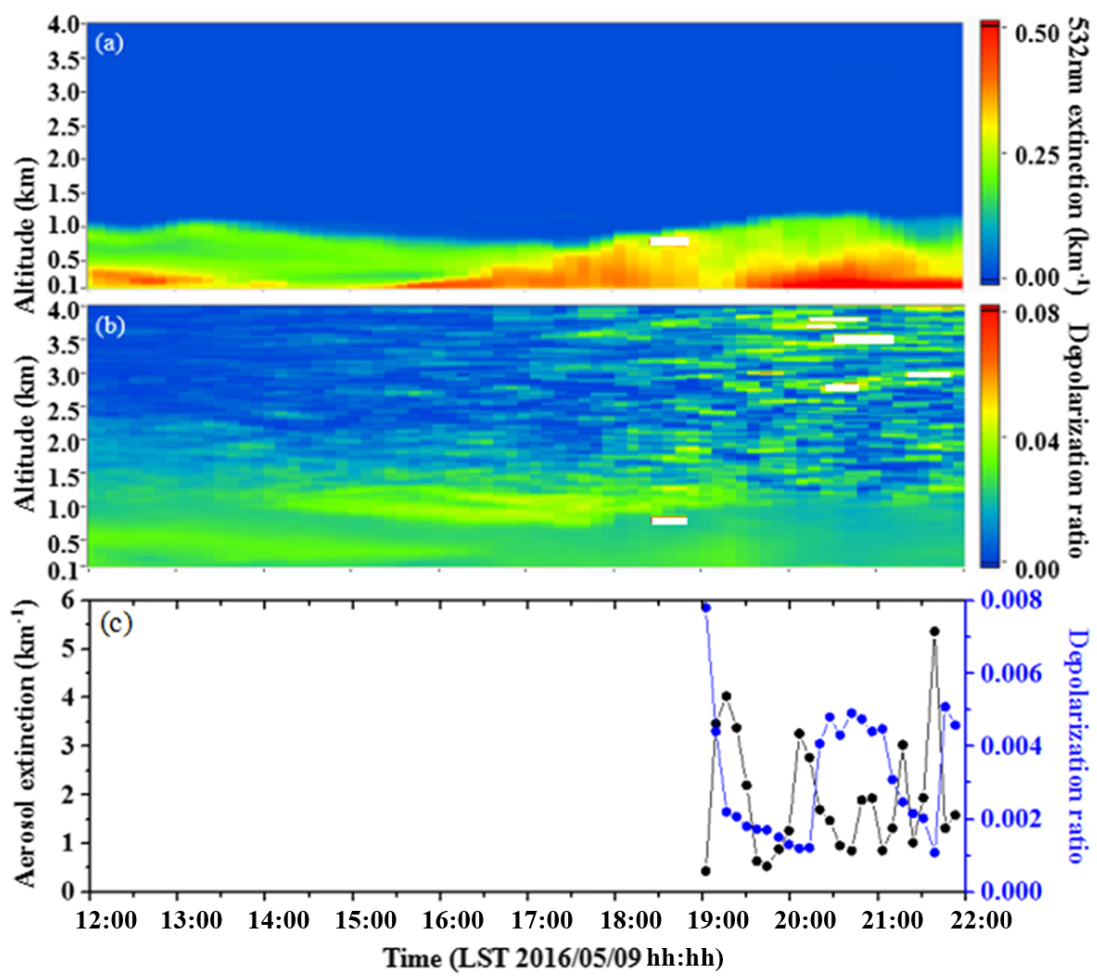

Figure 10. Aerosol extinction coefficient (a) and depolarization ratio (b) on 9 May. Panel (c) shows time series of aerosol extinction and depolarization ratios at $200 \mathrm{~m}$ from 19:00 to 22:00 on 9 May 2016. 
to the increase in $\mathrm{O}_{3}$ concentration. High HCHO levels during this time are mainly contributed by the oxidation of biogenic emissions of VOCs from plants, i.e., isoprene. The isoprene emission in the southern part of Shanghai was also reported to be higher than the northern part during summertime (Geng et al., 2011). Therefore, with the favorable meteorological conditions, a large abundance of VOCs and relatively strong radiance contribute to higher formation rates of $\mathrm{O}_{3}$ for case 2 on 18 May.

\subsection{Aerosol profile and evolution}

Aerosol depolarization profiles were measured using the Mie-elastic backscatter polarization lidar during the campaign. The depolarization ratio is an indicator of the sphericity of aerosols. A low depolarization ratio indicates that aerosols are spherical (Burton et al., 2012; Wong et al., 2017). Lidar results show that depolarization ratios of over $70 \%$ of measurements during the campaign are between 0.001 and 0.03 (see Fig. S5). This demonstrates that aerosols in the area were dominated by spherical particles. In general, there are five major spherical particles in the atmosphere, namely black carbon, organic carbon, sulfate, nitrate aerosols and sea salt. In the Shanghai area, sulfate, nitrate and ammonium together contributed to more than half of the total $\mathrm{PM}_{2.5}$ through the year, while the fraction of sea salt particles increased during clean days (Pathak et al., 2009; Tao et al., 2011; Han et al., 2015).

Figure 10a shows an enhancement of aerosol extinction from 19:00 to 22:00 on 9 May, while depolarization ratios at $200 \mathrm{~m}$ decreased during the same period in Fig. 10b. The growth of the extinction coefficient is due to the emission of biofuel-biomass burning in the surrounding agricultural areas (Du et al., 2011). However, the decrease in depolarization ratios is most likely due to the secondary processes in the atmosphere as the emission sources do not change rapidly. In Fig. 10c, the reduction of depolarization ratios is observed prior to the enhancement of the aerosol extinction coefficient from 19:00 to 22:00 on 9 May. The decrease in aerosol depolarization ratio indicates that the aerosols became more spherical during that time. It is related to the aerosol aging process, which is accompanied by the mixing between primary and secondary aerosols, as well as the interactions among aerosols, trace gases and moisture in the atmosphere. In addition, $\mathrm{NO}_{2}$ is an important precursor for atmospheric nitrate particle formation (Myoseon and Kamens, 2001; Wang et al., 2017). In order to determine the relationship between precursor gases and particles at different altitudes, correlation between $\mathrm{NO}_{2}$ concentrations and aerosol extinctions from 100 to $1000 \mathrm{~m}$ above ground level on 9 May is shown in Fig. S6. Moderate correlation is observed between ambient $\mathrm{NO}_{2}$ and aerosol $(R=0.63)$, indicating the feasible contribution of $\mathrm{NO}_{2}$ to the secondary aerosol formation from the ground level to higher altitudes. Under high atmospheric ozone conditions, ambient $\mathrm{NO}_{2}$ is oxidized rapidly to form nitrate aerosols in the atmosphere of Shanghai (Du et al., 2011). Nevertheless, more information such as in situ chemical composition and atmospheric conditions are needed for the investigation of the detailed secondary aerosol formation pathway.

\section{Summary and conclusions}

In this paper, we present measurements of $\mathrm{NO}_{2}$ and $\mathrm{HCHO}$ vertical profiles using ground-based MAX-DOAS, while aerosol and $\mathrm{O}_{3}$ profiles in Shanghai were measured using lidar from 5 to 23 May 2016. A sensitivity study shows that the a priori profile plays an important role in the aerosol profile retrieval. During the period of this campaign, the shapes of aerosol profiles are similar to Gaussian vertical distribution in Shanghai. Accurate aerosol extinction profiles were found to be very important for the retrieval of $\mathrm{NO}_{2}$ and $\mathrm{HCHO}$ vertical distribution. Simultaneous measurements of $\mathrm{NO}_{2}$ profiles obtained from balloon-based in situ instrument agree well with the MAX-DOAS data.

In order to validate the OMI $\mathrm{NO}_{2}$ VCDs, the OMI satellite products from USTC and NASA were compared to the ground-based MAX-DOAS observations. USTC OMI data, using corresponding local trace gas profiles for the AMF calculation, present better correlation $(R=0.95)$ than NASA OMI data $(R=0.71)$ with ground-based MAX-DOAS measurements. The improvement of USTC OMI NO 2 products is mainly related to the usage of localized $\mathrm{NO}_{2}$ and aerosol vertical profiles for the AMF calculation. According to the AMBTs analysis and the spatial distribution of averaged OMI tropospheric $\mathrm{NO}_{2} \mathrm{VCDs}$, the $\mathrm{NO}_{2}$ pollution at Fengxian was mainly influenced by transportation from industrial areas located in the north and northwest of Shanghai (Baoshan and Jiading) and the south of Jiangsu Province (e.g., Zhangjiagang).

$\mathrm{O}_{3}$ vertical profiles were measured using lidar. Based on the analysis of horizontal and vertical fluxes of ozone at different altitudes, we know that transportation is not a major influencing factor causing the increase in $\mathrm{O}_{3}$. Similar vertical distributions of $\mathrm{HCHO}$ and $\mathrm{O}_{3}$ indicate that local formation was the dominant ozone source during the time. Moreover, a secondary aerosol formation process was found based on the analysis of the aerosol extinction coefficient and depolarization ratios. A positive correlation between $\mathrm{NO}_{2}$ and aerosols during the campaign indicates the significant contribution of $\mathrm{NO}_{2}$ to total aerosols in the atmosphere.

Data availability. Data of MAX-DOAS and lidar measurements used in this study can be made available for scientific purposes upon request to the corresponding authors. Due to limited disk space, simulation results used for analyses will be deleted 1 year after the paper's publication. 


\section{The Supplement related to this article is available online at https://doi.org/10.5194/acp-17-14275-2017- supplement.}

Competing interests. The authors declare that they have no conflict of interest.

Special issue statement. This article is part of the special issue "Regional transport and transformation of air pollution in eastern China". It is not associated with a conference.

Acknowledgements. This research was supported by grants from the National Key Project of MOST (2016YFC0203302), National Natural Science Foundation of China (41575021, 91544212, 41405117) and the Key Project of CAS (KJZD-EW-TZ-G06-01). We acknowledge the NOAA Air Resources Laboratory (ARL) for making the HYSPLIT transport and dispersion model available on the internet (http://ready.arl.noaa.gov/). We thank the Shanghai Environment Monitoring Center, Nanjing University and East China University of Science and Technology for contributing to the balloon-based measurements. We would also like to thank the Hefei Institute of Physical Science, Chinese Academy of Sciences, for the technical support with the lidar measurements.

Edited by: Jianmin Chen

Reviewed by: two anonymous referees

\section{References}

Aliwell, S., Van Roozendael, M., Johnston, P., Richter, A., Wagner, T., Arlander, D., Burrows, J., Fish, D., Jones, R., and Tørnkvist, $\mathrm{K}$.: Analysis for $\mathrm{BrO}$ in zenith-sky spectra: An intercomparison exercise for analysis improvement, J. Geophys. Res., 107, 4199, https://doi.org/10.1029/2001JD000329, 2002.

Bobrowski, N., Hönninger, G., Galle, B., and Platt, U.: Detection of bromine monoxide in a volcanic plume, Nature, 423, 273-276, 2003.

Burton, S. P., Ferrare, R. A., Hostetler, C. A., Hair, J. W., Rogers, R. R., Obland, M. D., Butler, C. F., Cook, A. L., Harper, D. B., and Froyd, K. D.: Aerosol classification using airborne High Spectral Resolution Lidar measurements - methodology and examples, Atmos. Meas. Tech., 5, 73-98, https://doi.org/10.5194/amt-5-732012, 2012.

Chan, K. L., Hartl, A., Lam, Y. F., Xie, P. H., Liu, W. Q., Cheung, H. M., Lampel, J., Pöhler, D., Li, A., Xu, J., Zhou, H. J., Ning, Z., and Wenig, M. O.: Observations of tropospheric $\mathrm{NO}_{2}$ using ground based MAX-DOAS and OMI measurements during the Shanghai World Expo 2010, Atmos. Environ., 119, 45-58, 2015.

Clémer, K., Van Roozendael, M., Fayt, C., Hendrick, F., Hermans, C., Pinardi, G., Spurr, R., Wang, P., and De Mazière, M.: Multiple wavelength retrieval of tropospheric aerosol optical properties from MAXDOAS measurements in Beijing, Atmos. Meas. Tech., 3, 863-878, https://doi.org/10.5194/amt-3-863-2010, 2010.
Crutzen, P.: Physical and chemical processes which control the production, destruction and distribution of ozone and some other chemically active minor constituents, WMO The Phys. Basis of Climate and Climate Modelling 236-243 (SEE N 76-19675 1047), 1975.

Du, H., Kong, L., Cheng, T., Chen, J., Du, J., Li, L., Xia, X., Leng, C., and Huang, G.: Insights into summertime haze pollution events over Shanghai based on online water-soluble ionic composition of aerosols, Atmos. Environ., 45, 5131-5137, https://doi.org/10.1016/j.atmosenv.2011.06.027, 2011.

Duncan, B. N., Yoshida, Y., Olson, J. R., Sillman, S., Martin, R. V., Lamsal, L., Hu, Y., Pickering, K. E., Retscher, C., Allen, D. J., and Crawford, J. H.: Application of OMI observations to a spacebased indicator of $\mathrm{NO}_{x}$ and VOC controls on surface ozone formation, Atmos. Environ., 44, 2213-2223, 2010.

Fleischmann, O. C., Hartmann, M., Burrows, J. P., and Orphal, J.: New ultraviolet absorption cross-sections of $\mathrm{BrO}$ at atmospheric temperatures measured by time-windowing Fourier transform spectroscopy, J. Photoch. Photobio. A, 168, 117-132, 2004.

Frieß, U., Monks, P. S., Remedios, J. J., Rozanov, A., Sinreich, R., Wagner, T., and Platt, U.: MAX-DOAS $\mathrm{O}_{4}$ measurements: A new technique to derive information on atmospheric aerosols: 2. Modeling studies, J. Geophys. Res., 111, D14203, https://doi.org/10.1029/2005jd006618, 2006.

Frieß, U., Sihler, H., Sander, R., Pöhler, D., Yilmaz, S., and Platt, U.: The vertical distribution of $\mathrm{BrO}$ and aerosols in the Arctic: Measurements by active and passive differential optical absorption spectroscopy, J. Geophys. Res., 116, D00R04, https://doi.org/10.1029/2011JD015938, 2011.

Frieß, U., Klein Baltink, H., Beirle, S., Clémer, K., Hendrick, F., Henzing, B., Irie, H., de Leeuw, G., Li, A., Moerman, M. M., van Roozendael, M., Shaiganfar, R., Wagner, T., Wang, Y., Xie, P., Yilmaz, S., and Zieger, P.: Intercomparison of aerosol extinction profiles retrieved from MAX-DOAS measurements, Atmos. Meas. Tech., 9, 3205-3222, https://doi.org/10.5194/amt-9-32052016, 2016.

Geng, F., Zhao, C., Tang, X., Lu, G., and Tie, X.: Analysis of ozone and VOCs measured in Shanghai: A case study, Atmos. Environ., 41, 989-1001, 2007.

Geng, F., Tie, X., Xu, J., Zhou, G., Peng, L., Gao, W., Tang, X., and Zhao, C.: Characterizations of ozone, $\mathrm{NO}_{x}$, and VOCs measured in Shanghai, China, Atmos. Environ., 42, 6873-6883, 2008.

Geng, F., Tie, X., Guenther, A., Li, G., Cao, J., and Harley, P.: Effect of isoprene emissions from major forests on ozone formation in the city of Shanghai, China, Atmos. Chem. Phys., 11, 1044910459, https://doi.org/10.5194/acp-11-10449-2011, 2011.

Grell, G. A., Peckham, S. E., Schmitz, R., McKeen, S. A., Frost, G. Skamarock, W. C., and Eder, B.: Fully coupled "online" chemistry within the WRF model, Atmos. Environ., 39, 6957-6975, 2005.

Großmann, K., Frieß, U., Peters, E., Wittrock, F., Lampel, J., Yilmaz, S., Tschritter, J., Sommariva, R., von Glasow, R., Quack, B., Krüger, K., Pfeilsticker, K., and Platt, U.: Iodine monoxide in the Western Pacific marine boundary layer, Atmos. Chem. Phys., 13, 3363-3378, https://doi.org/10.5194/acp-13-3363-2013, 2013.

Han, T., Qiao, L., Zhou, M., Qu, Y., Du, J., Liu, X., Luo, S., Chen, C., Wang, H., Zhang, F., Yu, Q., and Wu, Q.: Chemical and optical properties of aerosols and their interrelationship in winter 
in the megacity Shanghai of China, J. Environ. Sci. (China), 27, 59-69, 2015.

Hao, N., Valks, P., Loyola, D., Cheng, Y., and Zimmer, W.: Space-based measurements of air quality during the World Expo 2010 in Shanghai, Environ. Res. Lett., 6, 044004, https://doi.org/10.1088/1748-9326/6/4/044004, 2011.

He, Q. S., Mao, J. T., Chen, J. Y., and Hu, Y. Y.: Observational and modeling studies of urban atmospheric boundary-layer height and its evolution mechanisms, Atmos. Environ., 40, 1064-1077, 2006.

Hendrick, F., Müller, J.-F., Clémer, K., Wang, P., De Mazière, M., Fayt, C., Gielen, C., Hermans, C., Ma, J. Z., Pinardi, G., Stavrakou, T., Vlemmix, T., and Van Roozendael, M.: Four years of ground-based MAX-DOAS observations of HONO and $\mathrm{NO}_{2}$ in the Beijing area, Atmos. Chem. Phys., 14, 765-781, https://doi.org/10.5194/acp-14-765-2014, 2014.

Hönninger, G. and Platt, U.: Observations of $\mathrm{BrO}$ and its vertical distribution during surface ozone depletion at Alert, Atmos. Environ., 36, 2481-2489, 2002.

Hönninger, G., von Friedeburg, C., and Platt, U.: Multi axis differential optical absorption spectroscopy (MAX-DOAS), Atmos. Chem. Phys., 4, 231-254, https://doi.org/10.5194/acp-4231-2004, 2004.

Irie, H., Kanaya, Y., Akimoto, H., Iwabuchi, H., Shimizu, A., and Aoki, K.: First retrieval of tropospheric aerosol profiles using MAX-DOAS and comparison with lidar and sky radiometer measurements, Atmos. Chem. Phys., 8, 341-350, https://doi.org/10.5194/acp-8-341-2008, 2008.

Jiang, F., Wang, T., Wang, T., Xie, M., and Zhao, H.: Numerical modeling of a continuous photochemical pollution episode in Hong Kong using WRF-chem, Atmos. Environ., 42, 8717-8727, 2008.

Kleinman, L. I., Daum, P. H., Lee, Y.-N., Nunnermacker, L. J., Springston, S. R., Weinstein-Lloyd, J., and Rudolph, J.: Sensitivity of ozone production rate to ozone precursors, Geophys. Res. Lett., 15, 2903-2906, https://doi.org/10.1029/2000GL012597, 2001.

Kramer, L. J., Leigh, R. J., Remedios, J. J., and Monks, P. S.: Comparison of OMI and ground-based in situ and MAX-DOAS measurements of tropospheric nitrogen dioxide in an urban area, J. Geophys. Res., 113, D16S39, https://doi.org/10.1029/2007JD009168, 2008.

Lee, H., Irie, H., Gu, M., Kim, J., and Hwang, J.: Remote sensing of tropospheric aerosol using UV MAX-DOAS during hazy conditions in winter: utilization of $\mathrm{O}_{4}$ absorption bands at wavelength intervals of 338-368 and 367-393 nm, Atmos. Environ., 45, 5760-5769, 2011.

Li, J., Fu, Q., Huo, J., Wang, D., Yang, W., Bian, Q., Duan, Y., Zhang, Y., Pan, J., Lin, Y., Huang, K., Bai, Z., Wang, S.-H., Fu, J. S., and Louie, P. K. K.: Tethered balloon-based black carbon profiles within the lower troposphere of Shanghai in the 2013 East China smog, Atmos. Environ., 123, 327-338, 2015.

Li, L., Chen, C. H., Fu, J. S., Huang, C., Streets, D. G., Huang, H. Y., Zhang, G. F., Wang, Y. J., Jang, C. J., Wang, H. L., Chen, Y. R., and Fu, J. M.: Air quality and emissions in the Yangtze River Delta, China, Atmos. Chem. Phys., 11, 16211639, https://doi.org/10.5194/acp-11-1621-2011, 2011.

Li, X., Brauers, T., Shao, M., Garland, R. M., Wagner, T., Deutschmann, T., and Wahner, A.: MAX-DOAS measurements in southern China: retrieval of aerosol extinctions and validation using ground-based in-situ data, Atmos. Chem. Phys., 10, 20792089, https://doi.org/10.5194/acp-10-2079-2010, 2010.

Li, X., Brauers, T., Hofzumahaus, A., Lu, K., Li, Y. P., Shao, M., Wagner, T., and Wahner, A.: MAX-DOAS measurements of $\mathrm{NO}_{2}, \mathrm{HCHO}$ and $\mathrm{CHOCHO}$ at a rural site in Southern China, Atmos. Chem. Phys., 13, 2133-2151, https://doi.org/10.5194/acp13-2133-2013, 2013.

Lin, J.-T., Martin, R. V., Boersma, K. F., Sneep, M., Stammes, P., Spurr, R., Wang, P., Van Roozendael, M., Clémer, K., and Irie, H.: Retrieving tropospheric nitrogen dioxide from the Ozone Monitoring Instrument: effects of aerosols, surface reflectance anisotropy, and vertical profile of nitrogen dioxide, Atmos. Chem. Phys., 14, 1441-1461, https://doi.org/10.5194/acp14-1441-2014, 2014.

Liu, H., Liu, C., Xie, Z., Li, Y., Huang, X., Wang, S., Xu, J., and Xie, P.: A paradox for air pollution controlling in China revealed by "APEC Blue" and "Parade Blue", Sci. Rep., 6, 34408, https://doi.org/10.1038/srep34408, 2016.

Ma, J. Z., Beirle, S., Jin, J. L., Shaiganfar, R., Yan, P., and Wagner, T.: Tropospheric $\mathrm{NO}_{2}$ vertical column densities over Beijing: results of the first three years of ground-based MAXDOAS measurements (2008-2011) and satellite validation, Atmos. Chem. Phys., 13, 1547-1567, https://doi.org/10.5194/acp13-1547-2013, 2013.

Mahajan, A. S., De Smedt, I., Biswas, M. S., Ghude, S., Fadnavis, S., Roy, C., and van Roozendael, M.: Inter-annual variations in satellite observations of nitrogen dioxide and formaldehyde over India, Atmos. Environ., 116, 194-201, https://doi.org/10.1016/j.atmosenv.2015.06.004, 2015.

Martin, R. V., Fiore, A. M., and Van Donkelaar, A.: Spacebased diagnosis of surface ozone sensitivity to anthropogenic emissions, Geophys. Res. Lett., 31, L06120, https://doi.org/10.1029/2004GL019416, 2004.

Meller, R. and Moortgat, G. K.: Temperature dependence of the absorption cross sections of formaldehyde between 223 and 323 $\mathrm{K}$ in the wavelength range $225-375 \mathrm{~nm}$, J. Geophys. Res., 105, 7089-7101, 2000.

Myoseon, J. and Kamens Richards, M.: Characterization of secondary aerosol from the photooxidation of toluene in the presence of $\mathrm{NO}_{x}$ and 1-Propene, Environ. Sci. Technol., 35, 36263639, 2001.

Pathak, R. K., Wu, W. S., and Wang, T.: Summertime $\mathrm{PM}_{2.5}$ ionic species in four major cities of China: nitrate formation in an ammonia-deficient atmosphere, Atmos. Chem. Phys., 9, 17111722, https://doi.org/10.5194/acp-9-1711-2009, 2009.

Platt, U. and Stutz, J.: Differential Optical Absorption Spectroscopy, Springer, Heidelberg, Berlin, 229-375, 2008.

Rodgers, C. D.: Inverse methods for atmospheric sounding: theory and practice, World Scientific Publishing, Singapore-New Jersey-London-Hong Kong, 2000.

Rothman, L., Gordon, I., Barber, R., Dothe, H., Gamache, R., Goldman, A., Perevalov, V., Tashkun, S., and Tennyson, J.: HITEMP, the high-temperature molecular spectroscopic database, J. Quant. Spectrosc. Ra., 111, 2139-2150, 2010.

Seinfeld, J. H. and Pandis, S. N.: Atmospheric Chemistry and Physics - From Air Pollution to Climate Change, John Wiley, New York, 1998. 
Serdyuchenko, A., Gorshelev, V., Weber, M., Chehade, W., and Burrows, J. P.: High spectral resolution ozone absorption crosssections - Part 2: Temperature dependence, Atmos. Meas. Tech., 7, 625-636, https://doi.org/10.5194/amt-7-625-2014, 2014.

Sillman, S.: The use of $\mathrm{NO}_{y}, \mathrm{H}_{2} \mathrm{O}_{2}$, and $\mathrm{HNO}_{3}$ as indicators for ozone- $\mathrm{NO}_{x}$-hydrocarbon sensitivity in urban locations, J. Geophys. Res., 100, 14175-14188, https://doi.org/10.1029/94JD02953, 1995.

Tang, G., Li, X., Wang, Y., Xin, J., and Ren, X.: Surface ozone trend details and interpretations in Beijing, 2001-2006, Atmos. Chem. Phys., 9, 8813-8823, https://doi.org/10.5194/acp-9-88132009, 2009.

Tang, G., Wang, Y., Li, X., Ji, D., Hsu, S., and Gao, X.: Spatialtemporal variations in surface ozone in Northern China as observed during 2009-2010 and possible implications for future air quality control strategies, Atmos. Chem. Phys., 12, 2757-2776, https://doi.org/10.5194/acp-12-2757-2012, 2012.

Tang, G., Zhu, X., Xin, J., Hu, B., Song, T., Sun, Y., Zhang, J., Wang, L., Cheng, M., Chao, N., Kong, L., Li, X., and Wang, Y.: Modelling study of boundary-layer ozone over northern China - Part I: Ozone budget in summer, Atmos. Res., 187, 128-137, https://doi.org/10.1016/j.atmosres.2016.10.017, 2017a.

Tang, G., Zhu, X., Xin, J., Hu, B., Song, T., Sun, Y., Wang, L., Wu, F., Sun, J., Cheng, M., Chao, N., Li, X., and Wang, Y.: Modelling study of boundary-layer ozone over northern China - Part II: Responses to emission reductions during the Beijing Olympics, Atmos. Res., 193, 83-93, https://doi.org/10.1016/j.atmosres.2017.02.014, 2017b.

Tao, S., Wang, X., Chen, H., Yang, X., Li, M., Li, L., and Zhou, Z.: Single particle analysis of ambient aerosols in Shanghai during the World Exposition, 2010: two case studies, Frontiers of Environmental Sciences \& Engineering in China, 4, 391-401, 2011.

Thalman, R. and Volkamer, R.: Temperature dependent absorption cross-sections of $\mathrm{O}_{2}-\mathrm{O}_{2}$ collision pairs between 340 and $630 \mathrm{~nm}$ and at atmospherically relevant pressure, Phys. Chem. Chem. Phys., 15, 15371-15381, 2013.

Vandaele, A. C., Hermans, C., Simon, P. C., Carleer, M., Colin, R., Fally, S., Merienne, M.-F., Jenouvrier, A., and Coquart, B.: Measurements of the $\mathrm{NO}_{2}$ absorption cross-section from $42000 \mathrm{~cm}^{-1}$ to $10000 \mathrm{~cm}^{-1}(238-1000 \mathrm{~nm})$ at $220 \mathrm{~K}$ and 294 K, J. Quant. Spectrosc. Ra., 59, 171-184, 1998.

Vlemmix, T., Hendrick, F., Pinardi, G., De Smedt, I., Fayt, C., Hermans, C., Piters, A., Wang, P., Levelt, P., and Van Roozendael, M.: MAX-DOAS observations of aerosols, formaldehyde and nitrogen dioxide in the Beijing area: comparison of two profile retrieval approaches, Atmos. Meas. Tech., 8, 941-963, https://doi.org/10.5194/amt-8-941-2015, 2015.

Wagner, T., Dix, B. v., Friedeburg, C. V., Frieß, U., Sanghavi, S., Sinreich, R., and Platt, U.: MAX-DOAS $\mathrm{O}_{4}$ measurements: A new technique to derive information on atmospheric aerosols-Principles and information content, J. Geophys. Res., 109, D22205, https://doi.org/10.1029/2004JD004904, 2004.

Wagner, T., Deutschmann, T., and Platt, U.: Determination of aerosol properties from MAX-DOAS observations of the Ring effect, Atmos. Meas. Tech., 2, 495-512, https://doi.org/10.5194/amt-2-495-2009, 2009.
Wagner, T., Beirle, S., Brauers, T., Deutschmann, T., Frieß, U., Hak, C., Halla, J. D., Heue, K. P., Junkermann, W., Li, X., Platt, U., and Pundt-Gruber, I.: Inversion of tropospheric profiles of aerosol extinction and $\mathrm{HCHO}$ and $\mathrm{NO}_{2}$ mixing ratios from MAX-DOAS observations in Milano during the summer of 2003 and comparison with independent data sets, Atmos. Meas. Tech., 4, 2685-2715, https://doi.org/10.5194/amt-4-2685-2011, 2011.

Wang, S., Cuevas, C. A., Frieß, U., and Saiz-Lopez, A.: MAXDOAS retrieval of aerosol extinction properties in Madrid, Spain, Atmos. Meas. Tech., 9, 5089-5101, https://doi.org/10.5194/amt9-5089-2016, 2016.

Wang, T., Hendrick, F., Wang, P., Tang, G., Clémer, K., Yu, H., Fayt, C., Hermans, C., Gielen, C., Müller, J.-F., Pinardi, G., Theys, N., Brenot, H., and Van Roozendael, M.: Evaluation of tropospheric $\mathrm{SO}_{2}$ retrieved from MAX-DOAS measurements in Xianghe, China, Atmos. Chem. Phys., 14, 11149-11164, https://doi.org/10.5194/acp-14-11149-2014, 2014.

Wang, Y., Lampel, J., Xie, P., Beirle, S., Li, A., Wu, D., and Wagner, T.: Ground-based MAX-DOAS observations of tropospheric aerosols, $\mathrm{NO}_{2}, \mathrm{SO}_{2}$ and $\mathrm{HCHO}$ in Wuxi, China, from 2011 to 2014, Atmos. Chem. Phys., 17, 2189-2215, https://doi.org/10.5194/acp-17-2189-2017, 2017.

Willmott, C. J.: On the validation of models, Phys. Geogr., 2, 184-194, http://www.tandfonline.com/doi/abs/10.1080/ 02723646.1981.10642213, 1981.

Wittrock, F., Oetjen, H., Richter, A., Fietkau, S., Medeke, T., Rozanov, A., and Burrows, J. P.: MAX-DOAS measurements of atmospheric trace gases in Ny-Ålesund - Radiative transfer studies and their application, Atmos. Chem. Phys., 4, 955-966, https://doi.org/10.5194/acp-4-955-2004, 2004.

Wong, M. S., Qin, K., Lian, H., Campbell, J. R., Lee, K. H., and Sheng, S.: Continuous ground-based aerosol Lidar observation during seasonal pollution events at Wuxi, China, Atmos. Environ., 154, 189-199, https://doi.org/10.1016/j.atmosenv.2017.01.051, 2017.

Xing, J., Wang, S. X., Jang, C., Zhu, Y., and Hao, J. M.: Nonlinear response of ozone to precursor emission changes in China: a modeling study using response surface methodology, Atmos. Chem. Phys., 11, 5027-5044, https://doi.org/10.5194/acp-115027-2011, 2011.

Zhang, R., Lei, W., Tie, X., and Hess, P.: Industrial emissions cause extreme urban ozone diurnal variability, P. Natl. Acad. Sci. USA, 101, 6346-6350, https://doi.org/10.1073/pnas.0401484101, 2004.

Zhu, X., Tang, G., Hu, B., Wang, L., Xin, J., Zhang, J., Liu, Z., Münkel, C., and Wang, Y.: Regional pollution and its formation mechanism over North China Plain: A case study with ceilometer observations and model simulations, J. Geophys. Res.-Atmos., 121, 14574-14588, https://doi.org/10.1002/2016JD025730, 2016. 